\title{
Historical overview of the Department of Neurosurgery at Yonsei University College of Medicine in the Republic of Korea
}

\author{
Dong Ah Shin, MD, PhD, and Dong Kyu Chin, MD, PhD \\ Department of Neurosurgery, Yonsei University College of Medicine, Seoul, Republic of Korea
}

Originally founded in 1885, Gwanghyewon later became the Severance Hospital (named after philanthropist Louis Severance, who supported and funded the construction of a modern hospital) and Yonsei University College of Medicine. The Department of Neurosurgery at Severance Hospital was established in 1957, and its residency program began in 1961. Currently, the Department of Neurosurgery has 34 professors and 17 fellows; specialties include vascular, functional, pediatric, tumor, skull base, and spine neurosurgery. With its state-of-the-art neurosurgical facilities and services, the Department of Neurosurgery has developed into a department of excellence within the Yonsei University Health System. In this vignette, the authors present a historic overview of the Department of Neurosurgery.

https://thejns.org/doi/abs/10.3171/2020.8.JNS201076

KEYWORDS history; Gwanghyewon; Severance Hospital; Yonsei University College of Medicine; Yonsei University Health System

$\mathrm{T}$ HE late 19th century in Korea was marked by Chosun's transition from a medieval to a modern dynasty. The Chosun Dynasty, which ruled the Korean Peninsula for 518 years, was occupied by Japan in 1910. The Japanese occupation ended with the conclusion of World War II in 1945. In 1948, the Republic of Korea was formally established. This period also involved enormous social and economic changes due to both internal and external pressures. This vigorous transformation brought forth modern medicine in Korea. The Gwanghyewon (House of Extended Grace) was originally founded in 1885 , and subsequently converted into the Severance Hospital and Yonsei University College of Medicine..$^{1-3}$ In 1957, the Department of Neurosurgery was established at Severance Hospital. ${ }^{4}$ In this vignette, we present a review of the department's history by collating and describing historical events.

\section{The Birth of Severance Hospital}

Horace Newton Allen, an American physician, was a missionary from a Presbyterian mission in New York (Fig. 1A). He successfully treated Queen Myeongseong's nephew, Young-ik Min, who was severely injured dur- ing a coup d'état in 1884 . The injury was so deep that it was difficult to treat the wound with traditional Korean medicine. At that time, experts specializing in Chinese oriental medicine, including herbal medications, acupuncture, and moxibustion, were in charge of public health in Chosun. Under the care of Horace Allen, Young-ik Min recovered completely within 3 months. King Gojong was deeply impressed by the modern medicine practiced by Horace Allen and consequently supported the establishment of Gwanghyewon in 1885, as Chosun's first modern hospital. ${ }^{1,5}$ Soon after its establishment, the hospital was renamed Chejungwon (or House of Civilized Virtue), and in 1886, it became Chejungwon Medical School, which was Korea's first Western-style medical school. ${ }^{5}$ Oliver R. Avison, a missionary doctor to Korea who was originally from the University of Toronto, became the fourth director of Chejungwon in 1893 (Fig. 1B). For 50 years, Avison worked tirelessly to bring modern medical practices and training to Korea. On September 3, 1904, the hospital was renamed Severance Hospital in honor of the benevolent American philanthropist Louis Henry Severance of the Standard Oil fortune (Figs. 1C and 2). The first 7 graduates in 1908 received doctor's licenses issued by the Korean government. The role of traditional medicine

ABBREVIATIONS WFNS $=$ World Federation of Neurosurgical Societies.

SUBMITTED April 24, 2020. ACCEPTED August 5, 2020.

INCLUDE WHEN CITING Published online January 22, 2021; DOI: 10.3171/2020.8.JNS201076. 

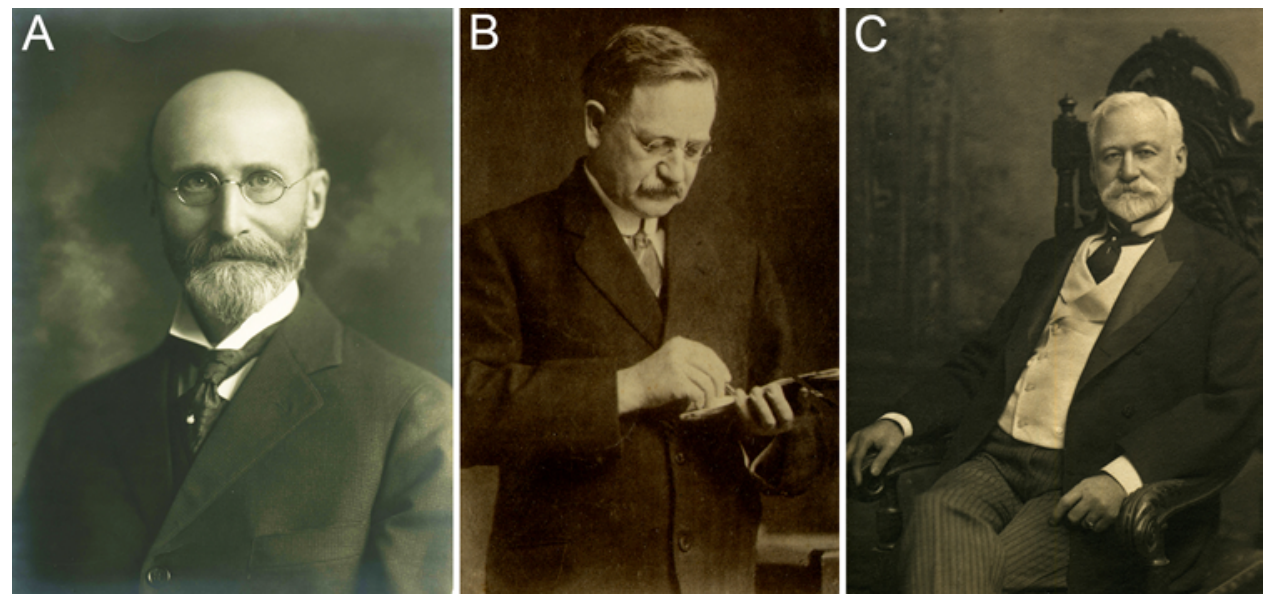

FIG. 1. A: Horace Newton Allen was an American Presbyterian missionary who studied medicine at Miami University. He introduced modern medical treatment to Korea through Chejungwon. B: Oliver R. Avison was a Canadian missionary and physician. He stayed in Korea from June 1892 to November 1935. He served as the Fourth General Director of Jejungwon. He laid the foundations of Yonsei University. C: Louis Henry Severance made a significant financial contribution to Chejungwon. His contribution was used to build a new Severance Hospital. After Severance's death, his son, John Severance, also made additional financial contributions to the hospital. Permission to use this image was obtained from the Dong-Eun Medical Museum, which belongs to Yonsei University. Figure is available in color online only.

has decreased since the introduction of Western medicine. During the Japanese occupation, public health was rapidly modernized by the government and missionaries. Japan eliminated oriental medicine from the public health system and built Western-style hospitals, mainly for the care of Japanese residents in Korea. In contrast, missionary doctors were actively spreading the knowledge of Western medicine for Korean habitats as a tool for religious work.

Severance Hospital evolved into the current Yonsei University Health System. This system consists of three colleges (Medicine, Dentistry, and Nursing) and four hos-

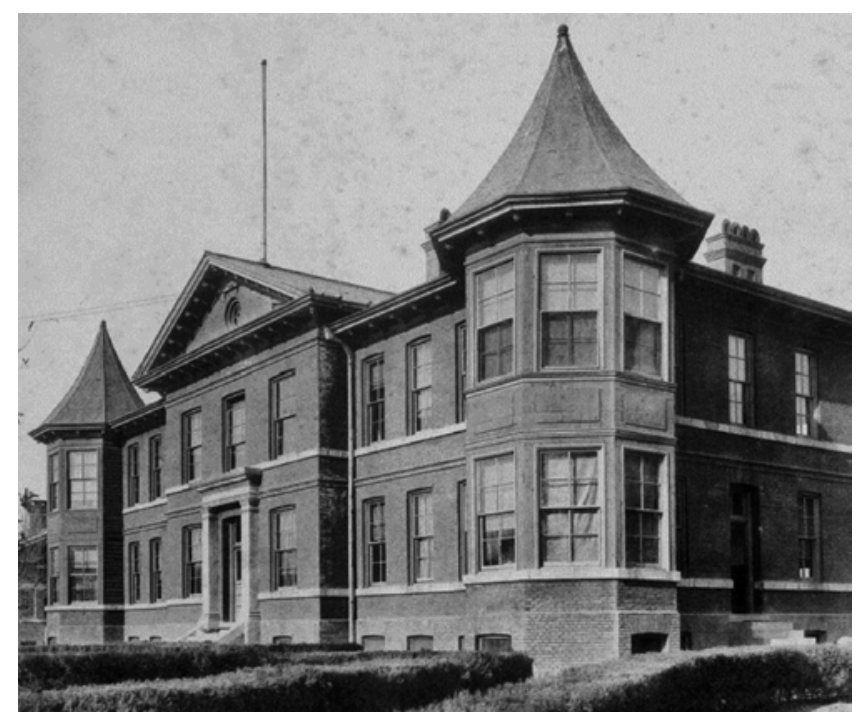

FIG. 2. Severance Hospital in 1904, which was built in front of Sungnyemun. Chejungwon was renamed as Severance Hospital on September 3, 1904. Permission to use this image was obtained from the Dong-Eun Medical Museum, which belongs to Yonsei University. pitals (Severance Hospital, Gangnam Severance Hospital, Yongin Severance Hospital, and the Dental Hospital).

\section{The Beginning of Neurosurgery at Severance Hospital}

According to the First Annual Report of Chejungwon Severance Hospital (formerly Gwanghyewon), many patients treated there in 1885 experienced neurological problems, including epilepsy, migraine, delirium, sciatica, back pain, and scoliosis. ${ }^{6}$ Oliver R. Avison, who became the director of the Chejungwon in 1894, treated neurological patients who had these and other ailments. Before the establishment of a neurosurgical specialty at Severance Hospital, neurosurgery was usually performed by general surgeons. ${ }^{4,7}$ In 1926 , Yong Sul Lee performed operations for several cases of spinal cord tumors. ${ }^{4} \mathrm{He}$ published the article, "Treatment for tubercular spine," in 1926. ${ }^{8}$ In 1932, Alfred Ludlow treated a case of cervical cord injury. ${ }^{4}$ "Three cases of cerebral concussion" was published by Dr. Peter Lew in 1934. " "On the brain tumors" was published by Dr. Chung Chul Lee in $1935 .^{10}$ The first brain surgery at Severance Hospital was performed by Ki Sup Lee in 1943.,11

\section{Establishment of the Department of Neurosurgery at Yonsei University}

During the Korean War, many Korean surgeons had the opportunity to observe the advanced neurosurgical and management skills of foreign neurosurgeons. ${ }^{12,13}$ The Korean War provided medical education to Korean doctors posted at dispatched hospitals, including the Mobile Army Surgical Hospital and the hospital ship Jutlandia. Some Korean surgeons also went abroad to study advanced neurosurgical practice in greater depth. ${ }^{13}$ Tai Jun Moon was one such pioneer (Fig. 3)..$^{12,14}$ In 1954, he visited the De- 


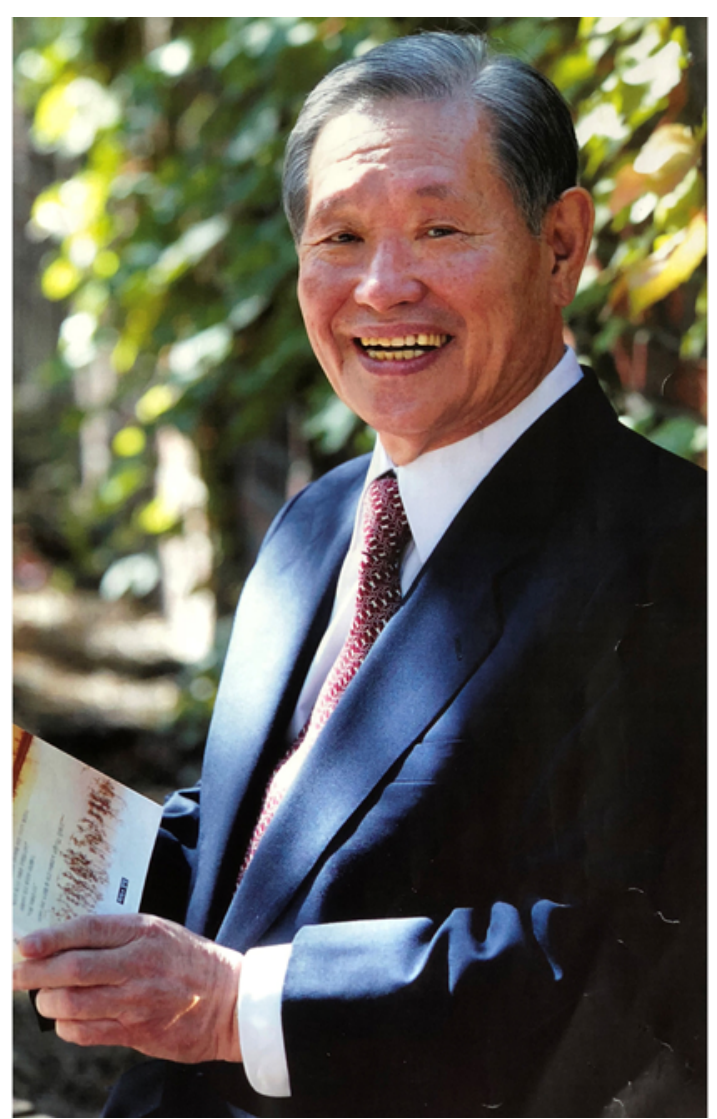

FIG. 3. Dr. Tai Joon Moon established the Department of Neurosurgery at Yonsei University, the first such department in Korea. He pioneered neurosurgery in Korea, established the Korean Board of Neurosurgery, and served as President of the Korean Neurosurgical Society, the Korean Medical Association, and the World Medical Association. He was also elected to serve as a senator in the Korean Assembly. Permission to use this image was obtained from Tai Joon Moon's family. Figure is available in color online only.

partment of Neurosurgery at Thomas Jefferson University Hospital in Philadelphia, Pennsylvania, where he was trained under the guidance of Rudolph Jaeger for 3 years. ${ }^{15}$ In 1957, he returned to Korea and started an independent neurosurgical service at Severance Hospital, which was equivalent to a neurosurgery division. In 1961, the Department of Neurosurgery was founded at Severance Hospital, and Tai Jun Moon served as the founding chairman. In the same year, a resident training program was also introduced. Dr. Kyu Woong Choi became the first resident. ${ }^{4}$ The residency program has, to date, produced more than 170 neurosurgeons who provide exemplary service at various institutions across the country. In 1964, direct intracranial aneurysm clipping was performed by Tai Jun Moon for the first time in the Republic of Korea. ${ }^{16}$

\section{The Evolution of the Neurosurgery Program at Yonsei University: The Lee Years}

Hun Jae Lee, the second chairman of the department (1966-1981), made several significant contributions to the department and aided its further growth (Fig. 4). ${ }^{17}$ During

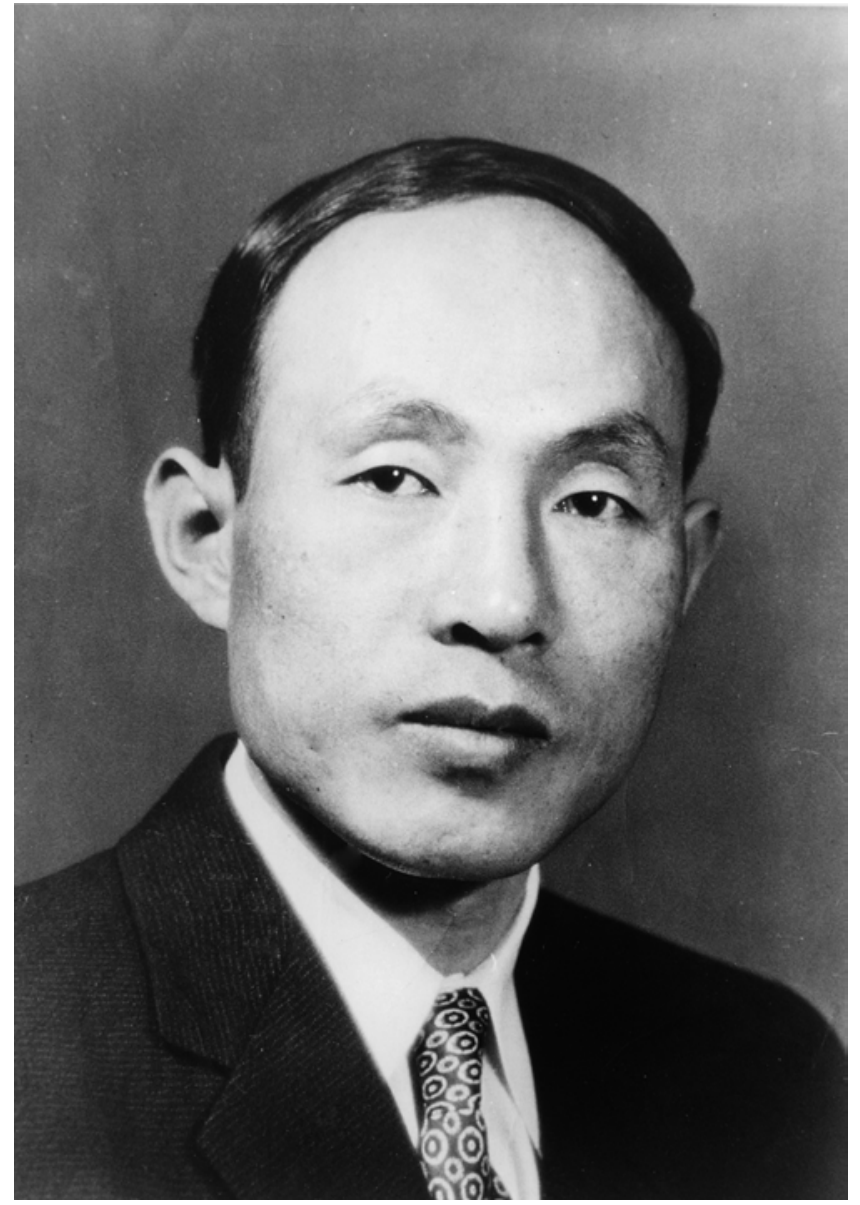

FIG. 4. Dr. Hun Jae Lee (November 11, 1921-March 13, 1983) is a key figure in the history of the Yonsei Department of Neurosurgery. He established the subspecialty system within the Department of Neurosurgery, which remains one of his most significant legacies. Reprinted with permission from Shin DA, Choi JU, Kim KS, Park HW. A great teacher of neurosurgery in Korea: Hun Jae Lee (1921-1983). Yonsei Med J. 2016 May;57(3):539-541. Copyright: Yonsei University College of Medicine 2016; CC BY-NC 3.0 (https://creativecommons.org/licenses/by-nc/3.0/).

the Korean war, he joined the army as a surgeon, where he gained considerable experience in neurosurgery at the Mobile Army Surgical Hospital. He then underwent resident training at the University of Michigan Medical School in Ann Arbor, Michigan, between 1955 and 1957. ${ }^{2,18} \mathrm{He}$ earned his American Board of Neurological Surgery accreditation in 1958. He was invited to Yonsei University to serve as the Chairman of the Department of Neurosurgery in 1966. Hun Jae Lee also served as one of the founding members of the Korean Neurological Society (established in 1961). Due to Lee's focus on the future and his powerful sense of intuition, the department developed markedly during the 17 years of his service, which concluded with him passing away in $1981 .{ }^{13}$

Hun Jae Lee also pioneered the establishment of subspecialty divisions, including vascular, functional, pediatric, and spine neurosurgery. By the early 1970s, highly specialized experts managed each subspecialty, as this system enabled faculty members to focus on their primary 
field of expertise. ${ }^{17}$ When selecting residents, Hun Jae Lee always chose one resident from remote cities of the country. His intention was to train residents across the country. ${ }^{17}$ As a result, Yonsei Neurosurgery alumni have been occupying important positions in major hospitals across the nation.

\section{Maturation of the Department's Subspecialty System}

Kyu Chang Lee became the third chairman (19811988), succeeding Hun Jae Lee. He returned to Korea in 1975 after studying neurophysiology for 3 years at the Max Planck Institute in Germany, under the guidance of Rolf Hassler. During his time in Germany, he visited Switzerland to learn the microsurgical aneurysm clipping technique from Gazi Yaşargil. This experience led him to become a neurovascular surgeon. Upon his return to Yonsei University, he introduced the classic pterional transsylvian approach, the concept of cisternal dissection, and the technique of microvascular anastomosis in Korea. ${ }^{16,19,20}$ Kyu Chang Lee had clipped 1000 intracranial aneurysms by 1992, and 2000 by 1999 . He also presided over the Sixth International Workshop on Cerebrovascular Surgery in Seoul in 2000.

The stereotactic and functional neurosurgery subdivision was established by Sang Sup Chung, the fourth departmental chairman (1988-1994). After completing his residency at Severance Hospital in 1970, he went to Edinburgh University to study stereotactic and functional neurosurgery under John Gillingham and Edward Hitchcock. ${ }^{4,21}$ After returning to Severance Hospital, he performed various functional neurosurgeries, including those for movement disorders, epilepsy, and pain. He performed radiosurgeries as well. ${ }^{22} \mathrm{He}$ was also an expert in microvascular decompression for the treatment of hemifacial spasms and trigeminal neuralgia, and he operated on more than 2000 patients with those conditions ${ }^{4,23} \mathrm{He}$ was the President of the Third Asian Society of Stereotactic, Functional, and Computer-Assisted Neurosurgery meeting, held in Seoul in 1999.

The modern history of spinal surgery at Yonsei University began with Young Soo Kim (the department's fifth chairman, 1994-2001). ${ }^{24} \mathrm{He}$ used a surgical microscope for a lumbar discectomy in 1975, which was the first microscopic discectomy performed in Korea. ${ }^{25,26}$ In 1980, with a scholarship from the British Council, he underwent further training for treating spinal cord injury at Stoke Mandeville Hospital in the United Kingdom. When Gangnam Severance Hospital was established in 1983, he was appointed as the head of the neurosurgery department. With Young Soo Kim's enthusiasm, the Yonsei Spine Institute was founded in 2003, and this institute developed into the Gangnam Severance Spine Hospital in 2005. Young Soo Kim introduced chemonucleolysis for the treatment of herniated lumbar discs in 1984, and he had performed surgery for more than 3000 such cases by $1990 .{ }^{27} \mathrm{He}$ was also the president of the Fourth International Neurotrauma Society meeting held in Seoul in 1997.

Joong Uhn Choi (the sixth chairman, 2001-2003) established the Division of Pediatric Neurosurgery. He un- derwent training at Queen Square, and SickKids Hospital at the University of Toronto, Canada, before returning to Korea in 1977. ${ }^{2,4}$ Under his leadership, Severance Hospital became a prominent center for treatment of patients with pediatric brain tumors, moyamoya disease, spasticity, pediatric epilepsy, dysraphism, other congenital anomalies, and pediatric neurotrauma. ${ }^{2,28-31}$ In 1985, he first introduced a radioisotope cisternogram grading system..$^{32}$ In addition, in 1989, he performed the first neuroendoscopy for hydrocephalus in Korea. ${ }^{33} \mathrm{He}$ was the first neurologist in the world to treat hypothalamic hamartomas using neuroendoscopy. ${ }^{30}$ Joong Uhn Choi also hosted the 19th International Society of Pediatric Neurosurgery meeting held in Seoul in 1991. ${ }^{2}$

In 1989, Kyu-Sung Lee (the seventh chairman, 20032007) introduced the surgery for skull base tumors in Korea. He was the first neurologist in Korea to perform cavernous sinus surgery and use the transpetrosal and farlateral transcondylar approaches. In 1993, he started the first cadaver dissection workshop for skull base surgery in Korea at Yonsei University to teach Korean neurosurgeons. With his efforts, the neurooncology division became the Neuro-oncology and Skull Base Surgery Center in 2005. ${ }^{4} \mathrm{He}$ was the president of the 14th Asian Australasian Congress of Neurological Surgeons, and the president of the 13th Asian Oceanian Congress of Skull Base Surgery held in Jeju Island, Korea, in 2015. He also served as the chair of the World Federation of Neurosurgical Societies (WFNS) Skull Base Surgery Committee. With his tireless efforts, the WFNS cadaver dissection course has been held in conjunction with the Korean Brain Tumor Society since 2008 . He is the honorary president of the Asian Australasian Society of Neurological Surgeons.

Currently, 34 professors and 17 fellows work in the Department of Neurosurgery. Their fields of expertise include vascular, functional, pediatric, tumor, skull base, and spinal neurosurgeries (Fig. 5). Last year alone, 98 research papers from this department were published in international journals. In the same year, a total of KRW $5,541,002,224$ ( $\$ 4,523,267$ US) was received as funding support by the department. Our department has the largest number of surgery cases in Korea and is involved in more than 9000 cases of elective surgery (Fig. 6). Inspired by the good will of Horace Newton Allen, Oliver R. Avison, and Louis Henry Severance, the Yonsei University Health System (Fig. 7) educates doctors from developing countries. Each year, more than 10 visiting scholars join the Department of Neurosurgery. We are actively involved in the teaching and training of neurosurgeons, as we have learned from our history and experience that education is the best way to share knowledge that will eventually lead to the evolution of neurosurgery. Our department has played a role in the activities of WFNS since 1989. In 2013, the 15th WFNS World Congress of Neurosurgery was held in Seoul. Just as Severance Hospital started as Allen's mission, Seung Kon Huh was sent by Severance Hospital Mission Centre to Tanzania in 2017. Presently, he works with local doctors, assisting them in the areas of education, research, and patient treatment, as well as performing other missionary activities. Since our founding, the Korean Neurosurgical Society has grown significantly, 


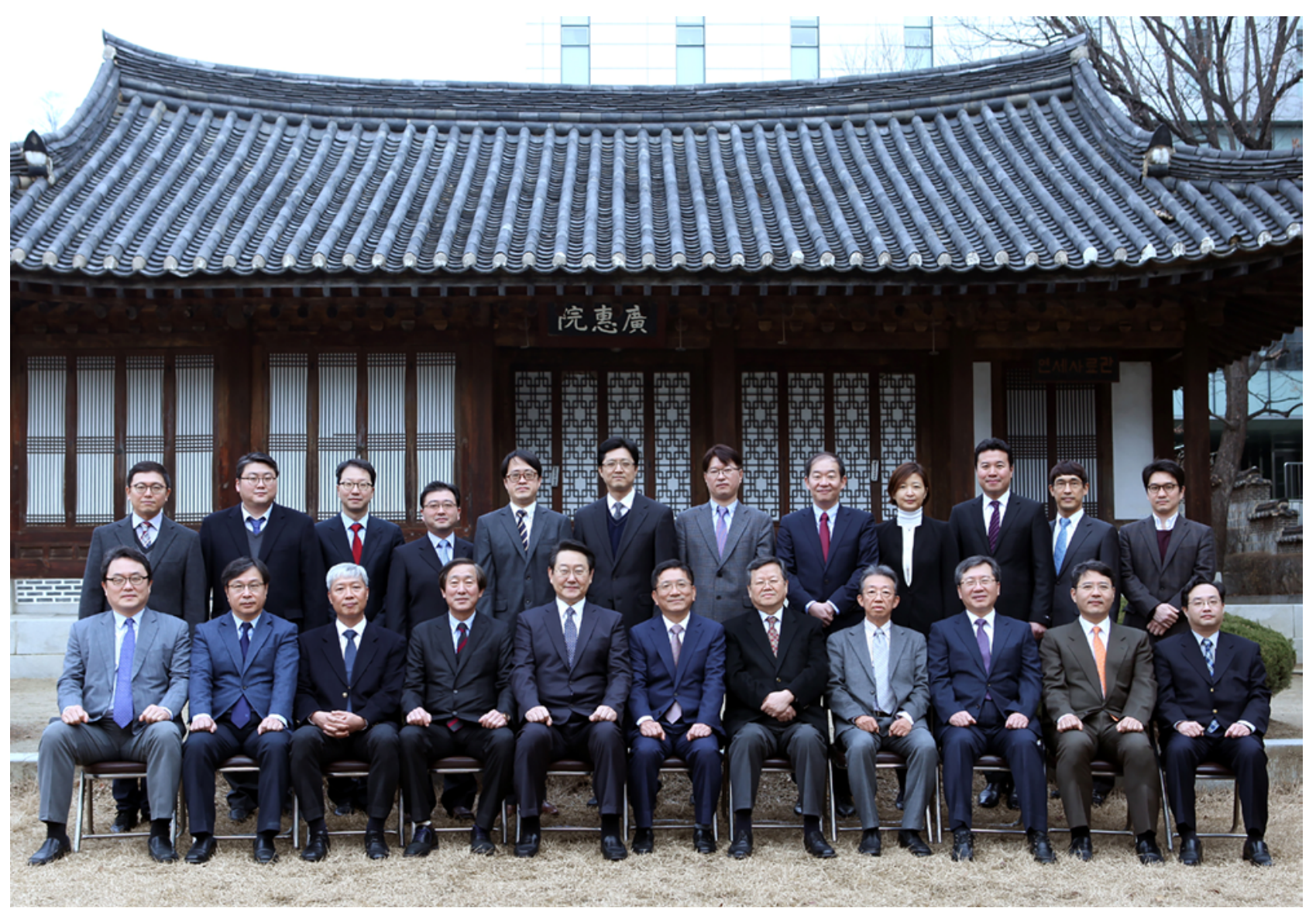

FIG. 5. A photograph of faculty members outside the restored Gwanghyewon on the campus of Yonsei University, taken January 2, 2016. Copyright owned by Yonsei University. Published with permission. Figure is available in color online only.
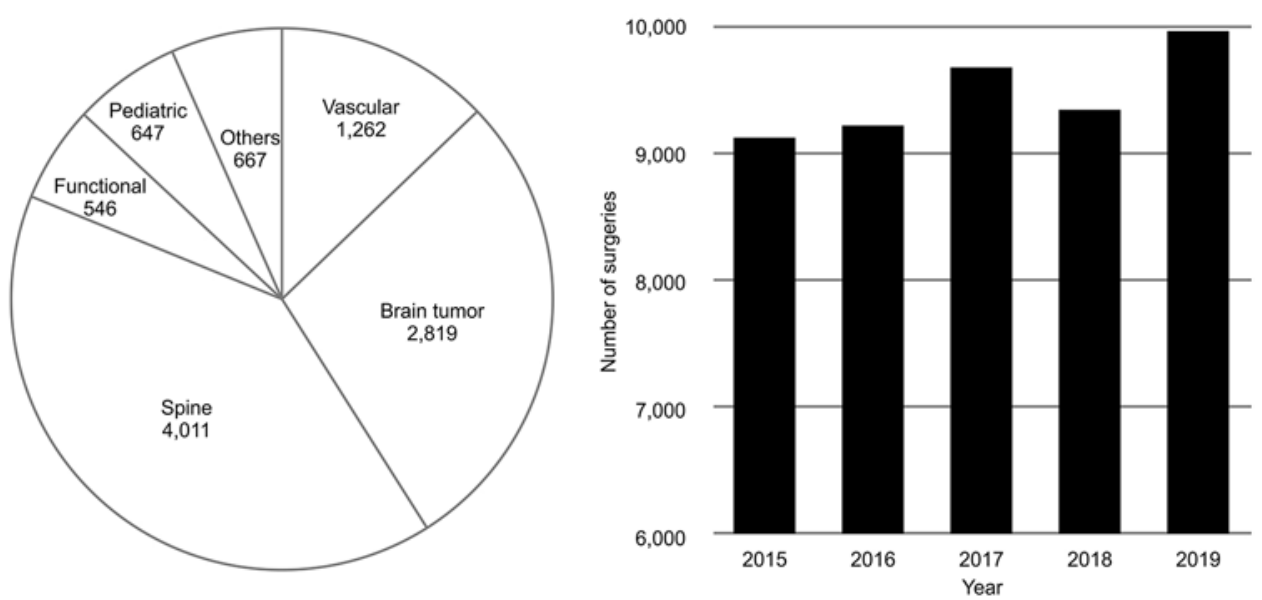

FIG. 6. Left: The number of operations performed by different subspecialties in 2016 at Yonsei University College of Medicine. Right: The total number of operations performed in each of the last 5 years. 


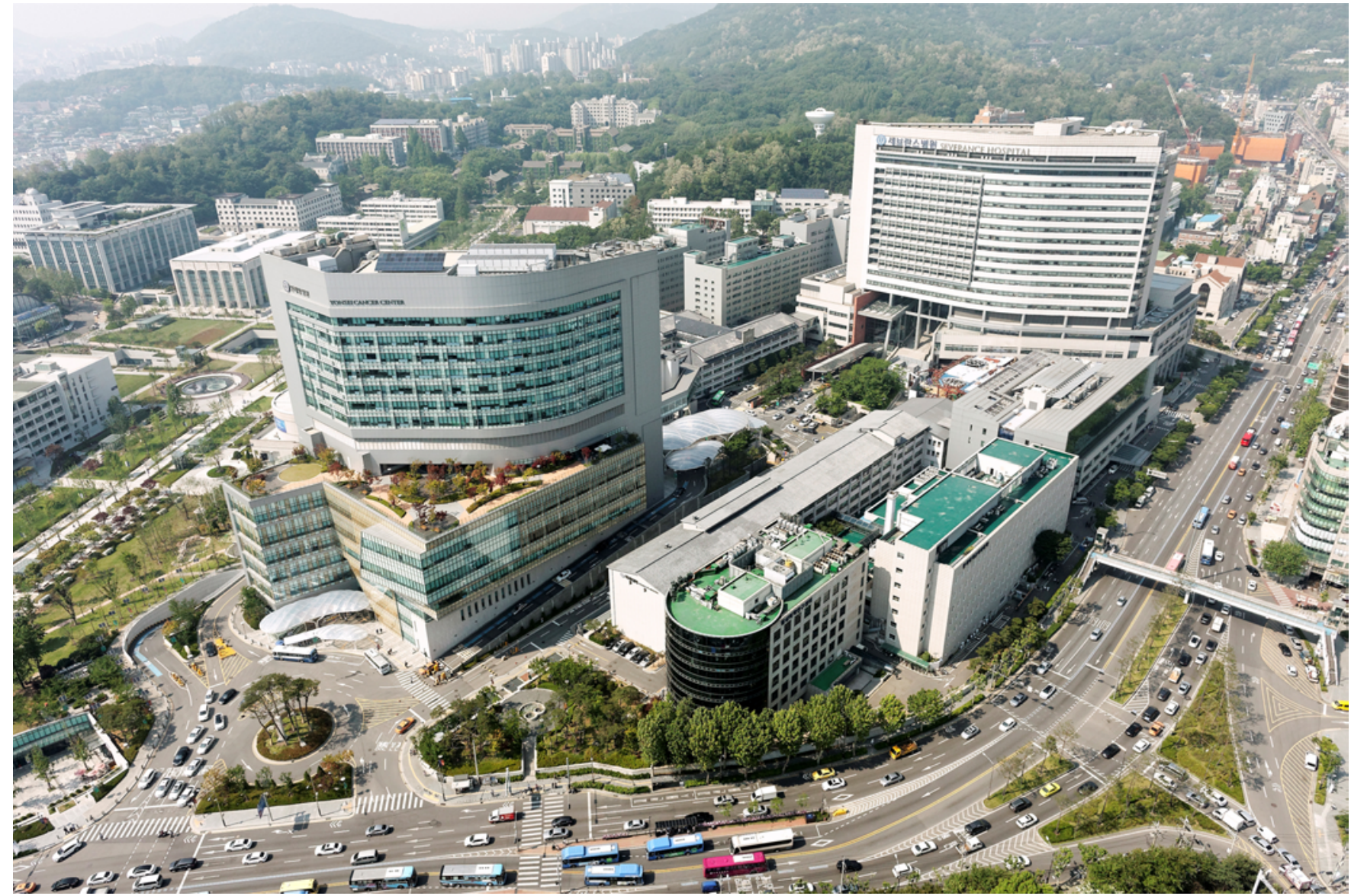

FIG. 7. An aerial view of Severance Hospital taken in March 2018. Photograph taken by Yonsei University. Permission to use this image was obtained from Yonsei University. Figure is available in color online only.

and as of 2019, it consists of 3169 board-certified members, 85 training institutions, 5 regional societies, and 12 subspecialty societies nationwide.

\section{Conclusions}

In this paper we present a general overview of the early history of neurosurgery and current status of the Department of Neurosurgery at Yonsei University. This article describes the clinical, academic, and scientific development of the department, including its present activities and future mission. The tradition of collaborative, benevolent, and cooperative efforts exercised by its founders and chairpersons will endure, as we continue to serve society with the goal of freeing our patients from disease and suffering.

\section{Acknowledgments}

We thank those who reviewed the manuscript, assisted in historical research, or provided photographs. The publication committee members included Jong Hee Chang, Won Seok Chang, Moo Sung Kang, Eui Hyun Kim, Yong Bae Kim, Keun Young Park, Kyu Won Shim, and Seong Yi. All of them are significant contributors to this paper. We are especially grateful to Joong Uhn Choi, Sang Sup Chung, Kyu-Sung Lee, and Keun Su Kim, whose support and encouragement made the writing of this paper possible. We would like to thank Editage for English-language editing.

\section{References}

1. Yeo IS. Severance Hospital: bringing modern medicine to Korea. Yonsei Med J. 2015;56(3):593-597.

2. Di Rocco C. Joon-Uhn Choi: The 2005-2006 ISPN President. Childs Nerv Syst. 2007;23(9):925-928.

3. Park HW, Yeo IS, Choi JU. The Department of Neurosurgery at Seoul National University: past, present, and future. Neurosurgery. 2003;52(5):1240-1241.

4. Department of Neurosurgery, Yonsei University. 50 Years History of Department of Neurosurgery in Yonsei University. ML Communications; 2007:63-71.

5. Park HW, Park YJ, Yeo IS, Kim IS. Medical education in Je Joon Won. Article in Korean. Uisahak. 1999;8(1):25-44.

6. Allen HN, Heron JW. First Annual Report of the Korean Government Hospital, Seoul. R Meiklejohn \& Co, 1886.

7. Park KB, Roh YH, Lee-Park O, Park S. History of neurosurgery in Democratic People's Republic of Korea. World Neurosurg. 2015;84(3):855-859.

8. Lee YS. Treatment for tubercular spine. The Severance Bulletin. 1926;8:1-4.

9. Lew P. Three cases of cerebral concussion. Korean Med J. $1934 ; 4: 74-84$

10. Lee CC. On the brain tumors. Korean Med J. 1935;5:65.

11. The Korean Neurosurgical Society. 40 Years History of the 
Korean Neurosurgical Society. Jungang Munhwasa; 2002: 3-258.

12. Lee HJ. 90 years history of Korean Medical Science. The KMA News. 1975:11. Accessed October 2, 2020. http://pdfs. doctorsnews.co.kr/1975/19750206/19750206_11.pdf

13. Sim BS. Perspectives in international neurosurgery: neurosurgery in the Republic of Korea (South Korea). Neurosurgery. 1979;5(1 Pt 1):75.

14. Hwang SN. History of Korean neurosurgery. World Neurosurg. 2015;84(2):192-196.

15. Chalouhi N, Osterholm J, Jabbour P, et al. History of the Department of Neurosurgery at Thomas Jefferson University Hospital. Neurosurgery. 2013;73(4):709-718.

16. Lee KC. Development of cerebrovascular surgery in Korea. Korean J Cerebrovasc Surg. 2005;7:5-11.

17. Shin DA, Choi JU, Kim KS, Park HW. A great teacher of neurosurgery in Korea: Hun Jae Lee (1921-1983). Yonsei Med J. 2016;57(3):539-541.

18. Kahn EA. Journal of a Neurosurgeon. Charles C Thomas; 1972.

19. Lee KC. The present and future of cerebrovascular surgery. $J$ Korean Neurosurg Soc. 2002;32(4):295-299.

20. Lee KC. The role of neurosurgeons in the era of endovascular treatment of cerebral aneurysms. Neurol Med Chir (Tokyo). 2002;42(5):242-243.

21. Hwang SN. History of Korean stereotactic and functional neurosurgery. Neurosurgery. 2005;56(2):406-409.

22. Chung SS. History of stereotactic surgery in Korea. In: Lozano M, Gildenberg PL, Tasker RR, eds. Textbook of Stereotactic and Functional Neurosurgery. Springer Berlin Heidelberg; 2009:171-178.

23. Chung SS, Chang JH, Choi JY, et al. Microvascular decompression for hemifacial spasm: a long-term follow-up of 1,169 consecutive cases. Stereotact Funct Neurosurg. 2001;77(1-4): 190-193.

24. Kim YS. A clinical study of intervertebral disc surgery based on 1500 cases. J Korean Neurosurg Soc. 1973;2(1):71-82.

25. Kim YS, Chung SS, Lee KC, Lee HJ. Experience with microsurgery in the herniations of lumbar, cervical and thoracic intervertebral discs. J Korean Neurosurg Soc. 1979;8(2): 299-306.

26. Kim YS, Lee KC. Microsurgical operation of herniated lumbar disc. J Korean Neurosurg Soc. 1982;11(4):515-521.
27. Kim YS, Chin DK, Yoon DH, et al. Predictors of successful outcome for lumbar chemonucleolysis: analysis of 3000 cases during the past 14 years. Neurosurgery. 2002;51(5)(suppl): S123-S128.

28. Choi JU, Kim DS, Chung SS, Kim TS. Treatment of germ cell tumors in the pineal region. Childs Nerv Syst. 1998;14(12):41-48.

29. Choi JU, Kim DS, Kim EY, Lee KC. Natural history of moyamoya disease: comparison of activity of daily living in surgery and non surgery groups. Clin Neurol Neurosurg. 1997; 99(2)(suppl 2):S11-S18.

30. Choi JU, Yang KH, Kim TG, et al. Endoscopic disconnection for hypothalamic hamartoma with intractable seizure. Report of four cases. J Neurosurg. 2004;100(5)(Suppl Pediatrics): $506-511$.

31. Shim KW, Park EK, Lee YH, et al. Treatment strategy for intracranial primary pure germinoma. Childs Nerv Syst. 2013; 29(2):239-248.

32. Matsumoto S, Tamaki N. Hydrocephalus. In: Matsumoto S, Tamaki N, eds. Hydrocephalus: Pathogenesis and Treatment. Springer Science \& Business Media; 2012.

33. Choi JU. Atlas of Practical Neuroendoscopy. Yonsei University Press; 2001.

\section{Disclosures}

The authors report no conflict of interest concerning the materials or methods used in this study or the findings specified in this paper.

\section{Author Contributions}

Conception and design: Shin. Acquisition of data: Shin. Analysis and interpretation of data: Shin. Drafting the article: Shin.

Critically revising the article: Chin. Reviewed submitted version of manuscript: Chin. Administrative/technical/material support: Chin. Study supervision: Chin.

\section{Correspondence}

Dong Kyu Chin: Gangnam Severance Hospital, Yonsei University College of Medicine, Seoul, Korea.dkchin@yuhs.ac. 